\title{
Creative Research in Papercut Art and Graphic Design
}

\author{
Chenyuan Guo
}

Yan'an University, Yan’an, Shaanxi, 716000

Keywords: Papercut Art, Graphic Design, Social Development

\begin{abstract}
The development of traditional folk paper-cut art in our country has a long history and is a folk art form that has been constantly developed by working people in order to satisfy their own material and spiritual pursuits and has originated in life and returned to life. As an image carrier of Chinese folk culture, folk paper-cut art is ubiquitous in the working people's life. With the development of society, folk art paper-cut gradually penetrates into modern design, which not only inherits traditional culture, but also has great enlightenment for the decoration, graphic, color and modeling language of modern graphic design.
\end{abstract}

\section{Introduction}

The meaning of folk paper-cut. Paper-cut refers to the paper as a processing object, with a knife as a tool for creative art, also known as carved paper. Paper-cut is to express their own artistic image through the cutout on the paper cut out. In the long-term social practice, the working people in our country constantly improve the form of folk paper-cut art with its own wisdom and diligence, and expand it to form a diversified paper-cut technique that uses hollow cut and cut.

The development of folk paper-cut. Before the Han Dynasty, the traditional paper-cut art of our country had appeared. The paper-cut materials were gold, silver and leather. After the Han Dynasty, paper began to be widely used in folk, but also become the material of paper-cut art. The earliest paper-cut in China occurred in the middle and late Northern Dynasties, about 1500 years ago. Folk paper-cut art in our country has developed from its origins to maturity and has become a favorite form of art by the public. It has become one of the most important folk art activities in China with rich and colorful forms of art and techniques of production. The traditional folk paper-cut art in our country originated from folk life and is developed continuously to meet its own material and spiritual pursuits. It is not restricted by utilitarian ideology and embodies the most basic aesthetic and spiritual qualities of mankind. With the progress of the times, the concept of folk paper-cutting and contemporary design continues to infiltrate and blend so that it has been reformed and developed. The traditional combination of traditional culture and modern science and technology in our country has made paper-cut art form a new story. The emergence of modern paper-cut is a milestone in the development of the new era of paper-cut, using different special paper texture and thickness, showing the modern rich inner world and a wide range of cultural connotations, making it a strong modern and rich level, At the same time it is interesting. Modern paper-cut paintings can also use wood, textile fabrics, metal, etc. to show the effect of paper cutting, which broke the previous paper only for the material boundaries.

\section{Modeling Language of Folk Paper - cut Art and Its Application in Modern Graphic Design}

The form of paper-cut art can be described as a "form of meaning", embodies the unique concept of paper-cut art, each piece has its own moral significance, emphasis on similarity and freehand, despise the shape and realism. Wang Guowei's "human speech" said that "the poet must care for himself in his natural life, and he must go beyond it. , So angry beyond the outside, it is highly coherent. "This passage fully expresses the essence of culture and art and the kernel is the soul of graphic design, and only familiar with traditional culture and traditional arts, Connotation of the classic. The unique shape of the folk paper-cut art can give endless inspiration to the modern 
graphic design and continuously inspire the designer's inspiration.

In the shape of the folk paper-cut also fully embodies the Chinese traditional folk culture concept of Taiji Yin and Yang theory. Due to the cultural consciousness and philosophical awakening of the pre-Qin era, this structural schema was sublimated to a metaphysical height and was abstracted as a "Tai Chi diagram." Taiji is such a succinct summary form of human, nature, society and universe that reflects the ancients' unique ways of grasping the world. The "yin and yang" characterizes the opposition of change, which shows that all living motions are derived from the principle of being opposed to each other. The ancients reflected the unpredictable laws of the universe in this round and round pattern. Gong Zi-zhen called the "everything from one stand, and then counter, three and beginning. ', (1) Here is the thing that is change, change, development, this change is one thing or another, complement each other, and later changed to the same as the beginning, Back to the original point of departure, the law for the beginning of the first and the second.This fully reflects the concept of positive and negative opposition, attached to the actual shape of virtual, real shape attached to the imaginary.The whole schema is rich in symbolic connotations and Aesthetic features, is the so-called "elephant invisible, loudly loudly." Under the influence of this concept of yin and yang taiji, in the folk paper-cut modeling embodies the void relatives and white when the black and white livelihood, the actual form of virtual existence Is a kind of spiritual hidden existence, it can be said is a subtle image .Finally, the paper-cut is very focused on the generalization and simplification but there is no lack of fine and fine cuttings, there are no lack of intentional layout of the business management scrutiny, so the work of Diao can ' Are all wonderful. "In the intent of the real at the same time, we should also understand the value of the void, is the so-called" know the white, keep its dark, "space-time at the more people can cause people to watch the interest.When the paper-cut in the real shape, Artists can exceed their potential and trends, Imaginary and real can break through the boundaries of space, into the human emotions .Virtual, real shape of the concept of interaction between yin and yang, requires the dependence of yin and yang, in the static state showed a very sense of rhythm and sense of movement. When counting the white when the relationship between black is reflected in the folk modeling methods we call "easy pictographic modeling method", which includes two aspects, one related to the morphology of the "simplified" after the yin and yang contrast, the bottom and the shape of each other Reflective Diao "can be reflected in this shape in the paper-cut is mainly reflected in positive and negative form of yin and yang shape of easy shape of the other meaning is related to the dynamic" abstraction "after the tai chi pattern, embodied in the paper-cut shape "S" tai chi pattern styling, about yin and yang tai chi this dynamic abstraction abstraction extract summarized as "'" curve, in the creation of the full use of "S" -shaped composition to the shape or silhouette in the paper-cut works, "happy meet" "Yin and Yang fish," "a whole two broken", "Japanese-shaped" and other shape formats, are the visual form of the yin and yang-Tai Chi structural mode of display.

\section{Enlightenment of Folk Paper - cut Art to Modern Graphic Design}

As a traditional folk art with a long history, the manifestation of folk paper-cutting art itself can bring certain enlightenment to the modern graphic design. This enlightenment can be summed up as a combination of decoration and function as a whole, Inheritance, and indirect forms of expression in three aspects for Chinese traditional art forms of folk paper-cut art itself appears in order to beautify and decorate the lives of our people based on this feature folk paper-cut art in building decoration, Stamp design, book decoration, product packaging and other fields to achieve the application of folk paper-cut art in these areas is essentially the application of modern graphic design are inspired by the use of folk paper-cut art image design stamps, combined with folk paper-cut art of thinking The modern graphic design such as building decoration originated from the influence of folk paper-cut art, which is essentially derived from the combination of decorative and functional folk-paper art.

In addition to the combination of decoration and function, the inspiration for the folk paper-cut art itself as a graphic vein can also bring enlightenment to the modern design of our country. In the 
traditional folk paper-cut art of China, such as the Longfeng and the Phoenix, the Eight Immortals crossed the sea are the more common designs If we integrate this kind of traditional design into modern graphic design, this kind of product that does not realize the better integration of traditional art and modern consciousness can not be called in essence the modern graphic design inspiration brought by folk paper-cut art. In fact, Through the art of paper-cutting to promote the development of modern graphic design related designers not only need to have a high level of awareness of folk paper-cut arts itself also need to have a more advanced design awareness only really grasp the artistic heritage of paper-cut art heritage can really Combined with the characteristics of folk paper-cut art to complete the modern graphic design.

For folk paper-cut art, because of its own limitations, folk-paper-cut art often can not carry out more complex screen performance, which also makes our country's folk paper-cut art has the characteristics of simple forms, but it is worth noting that the author The simplicity mentioned here does not mean monotonous. Under the influence of the simple characteristics of folk paper-cut art, the folk paper-cut art in our country must convey its own meaning through its own refinement, which makes the content and form of folk paper-cut art in a long period of development But it is also because of this unification that there is a big gap between folk paper-cut art and modern graphic design. It is not easy to integrate folk paper-cut art into modern graphic design. To understand the characteristics of the indirect summary form of folk paper-cut art, borrowing the connotation and morphological visual features of folk paper-cut art will reduce the entry of folk paper-cut art into the threshold of modern graphic design and truly realize the good integration of folk paper-cut art and modern graphic design.

In addition to the overall enlightenment that folk paper-cut art brings to modern graphic design, the modeling language of folk paper-cut art can also bring enlightenment to modern graphic design. For any art form, its most essential purpose is to conduct beautiful behaviors and Skill creation and display, and as the working people in our country thousands of years of life formed in the form of art, folk paper-cut art naturally belong to this category. Affected by the long history of inheritance, the folk paper-cut art in our country itself has a set of unique aesthetic standards and creative thinking modes, which can form a relatively perfect folk paper-cut artwork in the expression of external things , Combining with the aesthetic standards and creative thinking mode of folk paper-cut art, we can call it the modeling language of folk paper-cut art. In the folk paper-cut art of our country, Image-based modeling techniques, metaphorical image modeling techniques, image arrangement in limited forms and conformal innovation between shapes all belong to the more common folk-style paper-cut art modeling language. Folk folk paper-cutting art, such as "S" The shape itself is combined with the Tai Chi pattern to form a kind of aesthetic feature that the surface is still but the interior is endlessly moving. This feature of making the Tai Chi "S" of folk can be better applied to the modern graphic design through the relative completeness Absolutely complete aesthetic features will be applied folk too The characteristic of modern graphic design lies in the shape of "S". In symbolic image modeling technique, this stylistic language comes from the abstract emotional expression of folk paper-cut art, which belongs to the long Chinese nation In the process of development, the convention of common cultural symbols is concretely manifested. Combining with traditional cultural symbols can objectively reduce the difficulty of modern graphic design with folk paper-cut art. The relevant modern graphic design will also be imbued with oriental traditional flavor. In addition to the styling language, The color language of folk paper-cut art can also bring enlightenment to the modern graphic design. For the visual phenomenon of color, it can itself affect the emotional needs of human beings to some extent, and refers to the folk paper-cut art, the red is often the people The first color in mind, the color of auspiciousness, vitality, town evil, not "gaudy" itself derives from the accumulation of aesthetic taste in the Chinese nation for thousands of years as an art with the predominant color of red Form, our traditional folk paper-cut However, this color purity and the strong spiritual power contained in it make the artistic charm of folk paper-cut art to be further improved. For modern graphic design, the color of folk paper-cut art Revelation is mainly reflected in the three aspects of secular, penetrating, sentimental. 


\section{Conclusion}

In this paper, the folk paper-cut art on the modern graphic design enlightenment research, the author discusses in detail different from the modern cultural connotation of the unique art form of modern graphic design changes, this change essentially enhances the modern graphic design Artistic, but also for the relevant designers also put forward higher requirements, and want to truly achieve the goals of this article, the relevant personnel must vigorously carry out the essence of folk paper-cut learning.

\section{References}

[1] Xing Lizhi. On the folk paper-cut art of visual communication design inspiration [J] Journal of Liaocheng University (Social Science Edition) .2009 (02)

[2] Zhou Xu. On the traditional folk art language features [J]. Decoration. 2007 (05)

[3] LI Zhihong .Facial composition of paper-cut arts in the form of communication elements [J]. Panyu Polytechnic College 2005 (01)

[4] Jin Hui. Paper-cut art: from tradition to contemporary context [J] .Journal of South China Normal University (Social Science). 2004 (04)

[5] Yuan Ling, Fang Yan. Chinese traditional folk paper-cut art and modern graphic design [J] Beauty and Times. 2004 (06)

[6] Lv Yan. On the art of Chinese folk paper-cut characteristics [J]. Grand Fine Arts. 2004 (04) 